\title{
The Methodological Pluralism of Chemistry and Its Philosophical Implications
}

Joachim Schummer

js@hyle.org

\begin{abstract}
In this paper I first point out the pluralist constitution of science in general and of chemistry in particular and then argue that it is inevitable for epistemological reasons. Once methodological pluralism is accepted, many mainstream philosophical debates that are based on methodological monism become futile, of which I discuss "laws of nature", "reductionism", and "scientific realism". That shifts philosophical debates to more useful issues, such as the methodology of models, improving interdisciplinarity, and forms of philosophical realism that are institutionalized in scientific practice. I conclude that pluralism is the better way of doing and understanding science.
\end{abstract}

\section{Introduction}

Much of today's mainstream philosophy of science is still built on the normative assumption that science should develop one comprehensive and logically consistent image of the world. Because there is only one world, science must strive for its perfect image to be pursued by the best method, the primary rule of which requires that contradictory views should be avoided or eliminated. For philosophers, methodology thus came to be known as the art of evaluating competing images or theories, with the double implication that in the end one such method could ideally lead to one perfect theory (methodological monism). In contrast, scientists consider methodology the art of raising and solving epistemic issues, from formulating interesting research questions, to planning and conducting experimental research and discussing their results. As diverse as the research methods are, as diverse are at least the results.

Methodological pluralism, as understood in this paper, comprises both the diversities of research approaches and the resulting views on the world. The case of chemistry is particularly apt to illustrate pluralism of various kinds, such that this paper only adds to a longer list of previous work (e.g. Bacheard 1931, Hoffmann \& Laszlo 1991, Chang 2012). As pluralism slowly gains acceptance in mainstream philosophy (e.g. Kellert et al. 2006), chemistry is expected to attract more attention, because there are valuable philosophical lessons to learn from it.

In the following I will first point out the pluralist constitution of science in general and of chemistry in particular and then argue that it is inevitable for epistemological reasons (Section 1-3). Once methodological pluralism is accepted, many mainstream philosophical debates that are based on monism become futile, of which I discuss "laws of nature", "reductionism", and "scientific realism" (Sections 4-6). That shifts philosophical debates to more useful issues, such as the methodology of models, improving interdisciplinarity, and institutionalized forms of philosophical realism. The conclusion summarizes these and other advantages of pluralism as the better way of doing and understanding science.

\section{The Pluralist Constitution of Science}

Science as a whole is a pluralist enterprise. At least since the 19th-century, it regularly splits into different disciplines, subdisciplines, and research fields. Growing on average at an annual 
rate of 4-5 percent over several centuries, the number of papers, scientists, fields, etc. roughly double every 15 years (Price 1961). As a human endeavor science depends on the limited intellectual and social capacities of its members. If you want to keep up with the latest work, you can read at most a few hundred or thousand papers a year. However, in chemistry alone more than one million publications appear annually, covered by Chemical Abstracts. If you want to find agreements with your colleagues on what are important research questions, what needs to be done or improved in the future, or what should be standards of sound argumentation and experimentation, you can personally discuss all that with hardly more than a few hundred colleagues despite modern communication technology. As long as science grows and reading and discussing are prerequisites of doing research, the fragmentation of science is an unavoidable process.

On the one hand, the ongoing splitting follows a division of labor. Different subdisciplines study different subject matter and develop their own research questions as well as their corresponding conceptual apparatus and methods. Sometimes they focus on entirely different objects, as did organic and inorganic chemistry, such that under the common umbrella of general chemistry the fields, neatly separated, could complement each other without competition or disagreement - before the rise of organometallic, metalorganic, bioinorganic, biometalorganic etc. chemistry. Or, as in kinetics and thermodynamics, they study the same objects, i.e. chemical reactions, from different but complementary perspectives. On the other hand, a field can also split up because there is disagreement on the conceptual framework, such that one group prefers a new frame whereas the other sticks to the old one. A case in point is the mid-20th-century separation of molecular biology from biochemistry. While the latter continued the study of chemical processes in living organisms in terms of reaction pathways, i.e. the transformation and migration of matter, the former built its disciplinary identity on the conceptual framework of information transfer (Fox Keller 2000). Given the rapid growth and unavoidable fragmentation of science, it is likely that most cases of conceptual disagreement and conflict follow this kind of pattern. That is in strong contrast to the winner/looser stories of Popper, Kuhn and the like, who assumed that science would always (have to) pursue unity by eliminating competitors. While the received philosophies of science have presupposed strict conceptual unity in their own pictures, including Kuhn's notion that temporary crises turn into new types of "normal science", the actual science is the result of an ongoing process of fragmentation, because that has always been the obvious way of solving conceptual disagreement under the pressure of growth.

How much the received philosophy has left science in the dark comes to the fore in the manifold obstacles faced by interdisciplinary research. What once split into parts frequently out of historically contingent reasons, is later required to collaborate on cross-disciplinary issues that are increasingly posed from science policy. The barriers of cross-disciplinary communication are enormous (Schummer 2008). That does not only include differences in knowledge and expertise, which a smart division of labor management could possibly fix. In addition, the same terms, like "molecules", frequently have different meanings in the disciplines, depending on the theoretical context they are embedded in, which easily results in misunderstanding and confusion. Moreover, disciplines differ in the way they approach a problem, what they consider a satisfying answer or sound argument, and, more generally, what counts as important research questions worth pursuing. Thus, besides differences in knowledge and linguistic meaning, disciplines have distinctive ideas about methods and epistemic values that have steadily been developed through internal discussion.

One cannot solve those serious problems by claiming that the world consists of a certain set of building blocks to be investigated by a universal scientific method, if the building blocks and methods happened to be just from a single discipline. It does not help either to hope that all problems will disappear in the future by a not yet found universal Theory of Everything. Those who do so close their eyes to the fact that the development of 
modern science has been over several centuries a fragmentation into an ever growing plurality of scientific approaches with no interest at all in a universal theory, but strong inclinations and inner forces to continue so in the foreseeable future. Philosophy of science would be better off, and more useful, if it acknowledges and studies the pluralistic constitution of science.

\section{The Pluralist Constitution of Chemistry}

What has been said about science in general correspondingly holds for a mega-discipline such as chemistry. Regarding the number of publications, chemistry has long been as big as the rest of the sciences altogether (Schummer 2004). The production of more than a million publications per year requires a breakdown into hundreds of specialized fields, if results are to be read and discussed in a scholarly manner. Many divisions result from disagreement on conceptual frameworks in the past. However, even if such breakdowns were once systematically achieved, later research frequently blurs or overcomes clear-cut boundaries, as the outdated distinction between organic and inorganic chemistry illustrates. Rather than being reunited, typically those fields each follow their own paths because they have developed distinctive disciplinary approaches, research goals, and conceptual frameworks. Some focus on quantitative prediction as their major research goal, as in computer modeling. Others are interested in explanation by, for instance, studying the mechanism of chemical processes. Issues of classification, either of substances or of reactions, dominate many fields, whereas others look upon that from the specific point of improving synthetic capacities. There are fields of chemistry studying phenomena that probably do not occur outside the laboratory, as well as fields that define their identity by certain areas of nature, like bio-, geo- and astrochemistry, or of industrial application, such as pharmaceutical or polymer chemistry. Further, a broad range of chemical fields transgress disciplinary boundaries and adopt ideas, aims, and methods from their neighboring sciences, like physical chemistry and mathematical chemistry.

While such a kind of pluralism might discomfort the monist philosopher, it only illustrates the manifold goals and uses of science. The fact that the actual science pursues a variety of epistemic purposes, other than the so-called "truth of theories", in an undogmatic manner, makes it useful and flexible enough to address current and newly emerging problems. Even if we zoom in and look closer at the conceptual apparatus of individual fields, pluralism shows up.

Hasok Chang (2012) has shown in much detail for three important episodes in the history of chemistry - the Chemical Revolution, early electrochemistry, and the development of atomic and constitutional chemistry - how pluralist competition and interaction enabled the successful development of central concepts and theoretical approaches in chemistry. Rather than ending such competitions by electing a winner, chemists have frequently elaborated on the competitors and turned them into alternative models that are each tailored to specific aims and research questions. An almost arbitrary look into chemical textbooks reveals the obvious (Schummer 1998a). In inorganic chemistry, for instance, various theoretically guided concepts or models of what acids and bases are, compete with each other, such as those by Brønsted, Lewis, Pearson, and many others. Yet the competition is not about who is right or wrong, but about where exactly which model is more useful in explanations and predictions. Similar choices can be made between ligand theory and crystal field theory in chemistry of complex compounds; between the models of Freundlich, Langmuir, BET, etc. in adsorption theory; between collision and transition state theory in chemical kinetics; between a huge range of equations of state (from the simple ideal gas law, to the equations of van der Waals, Peng-Robinson-Stryjek-Vera, and dozens more) in thermodynamics; between molecular orbital, valence bond, and density functional theory in quantum chemistry, each including a variety of specific models; etc. 
The case of molecular structure might illustrate further how the pluralism of models works in chemistry (Schummer 1998b). Since the mid-19th century organic chemists have developed classical chemical structure theory that assigns to each compound a molecular structure, based on its elemental composition and chemical reaction properties. In this theory, a molecular structure is not simply a spatial arrangement of atoms, but an arrangement of socalled functional groups that represent the substance's chemical reactivities, which in turn are modeled by a growing set of standardized reaction mechanisms. The theory does not only provide explanations and predictions of chemical properties, it also allows planning and guiding chemical synthesis of hitherto unknown compounds. Indeed, tens of millions of new compounds have been predicted and synthesized by that approach. In contrast, quantum chemical modeling of molecular structure provides a unique approach to the explanation and prediction of electromagnetic and many thermodynamic properties, but is still rather poor regarding chemical transformations. That is not only a theoretical division of labor according to different kinds of properties to be dealt with by different approaches. The case of chemical structure theory illustrates that chemistry is not only about explanations and predictions. Instead, theoretical concepts are also developed and judged here according to their potential for synthesis, a major activity of chemists for various, mostly nontechnological ends (Schummer 1997, 2004). Moreover, theoretical concepts are expected to provide a basis for classification, to distinguish unambiguously between myriads of substances (Schummer 2004). The various subdisciplines of chemistry have further developed dozens of different kinds of molecular models and representations, from solid state chemistry to biochemistry, that each serves specific disciplinary needs and purposes (Hoffmann \& Laszlo 1991).

\section{The Inevitability of Pluralism}

There are two reasons why methodological pluralism is inevitable in chemistry: one relates to its multiple purposes, the other is grounded in the limits of chemical knowledge as a matter of principle.

The first reason is obvious from the aforementioned. Because chemistry pursues different goals, we need specialized approaches to achieve each one best. The argument requires different aims being logically independent from each other, such that achieving one does not automatically achieve the other. Although that is difficult to demonstrate in general, one can show at least for some instances that the parallel pursuit of different goals can easily run into conflicts. For example, a useful classification requires distinctive qualitative concepts, whereas precise predictions necessitate quantitative concepts. If synthesis is the main aim, all concepts must be operational such that theoretical conclusions can be translated into experimental operations, which is not required for classification, prediction, and explanation. Explanations in turn need causal concepts that are frequently obsolete in classification. Pursuing technological aims requires at least some utilitarian concepts that are useless and sometimes distorting in other projects, and so on.

If we accept the pluralism of aims or purposes in chemistry, we must reject the idea that there is a superior aim, say TRUTH, whose eventual achievement would automatically meet all the other epistemic needs best. Such a superior aim is not known in chemistry. If somebody claimed that, it could only be either the logical combination of all known aims, and thus would be obsolete, or the favorite purpose of one specialized field, which for the whole of chemistry would then be equally ranked with all the other aims. However, although the different aims are logically independent from each other, the pursuit of one can be useful for that of others (Schummer 2014a, chap. 11). For instance, working on causal explanations can make predictions more reliable than those that are based on mere statistical correlations. In turn, improving predictive capacities, including merely statistical error estimates, considerably helps the design and control of experiments conducted for the purpose of explanation or synthesis. Also synthesis and classification can mutually benefit each other, 
when synthesis reveals new, unexpected substance classes or when classification allows one to derive synthetic goals. Similarly, technological aims frequently inspire explanatory, predictive, synthetic, or classificatory work, and vice versa. Although methodological pluralism is inevitable in chemistry, that does not mean that all approaches follow paths independent from one another. Instead, they can mutual benefit each other by complementary assistance, which is, like the modern division of labor in economics, much more beneficial for the entire endeavor of science than the pursuit of obscure aims such as TRUTH.

The second reason why methodological pluralism is inevitable in chemistry refers to its epistemic limits. Historically the limits of scientific knowledge were the central topic of epistemology, from medieval debates on the relationship between science and theology to Kant's Critique of Pure Reason, before it became outmoded by ambitious philosophies and popularizations of physics. However, an approach that does not know its limits and instead promises universal applicability without scientific arguments, belongs to speculative philosophy or simplistic popularization rather than to science. While it is the job of each science to define the limits of applicability of its individual theories or models (see below), it is up to epistemology to identify fundamental limits of knowledge that cannot be overcome.

There are several such limits of chemical knowledge (Schummer 2010), of which one is particularly important here: the unbridgeable gap between the concepts and objects of chemistry. The general issue has a long tradition in philosophy, most prominently in the metaphysical realism/nominalism debate (Section 7). However, in chemistry we have a privileged access of analysis that allows conclusions beyond metaphysical speculations. For, chemistry has addressed the realism/nominalism issue, which is sometimes misleadingly called the issue of natural kinds, by experimental means, largely unnoticed by mainstream philosophy. Rather than only adjusting our concepts to the world as it is, chemistry also adjusts the world to its concepts by creating experimental systems that best fit its frameworks (Schummer 2010). Most importantly, the objects of experimental investigations are the end results of sophisticated purification procedures: pure substances or fabricated mixtures thereof. Because every concept of modern chemistry, both empirical and theoretical, is based on the notion of pure substances, the strategy seems to be ideal. It has its price, however, because there are, strictly speaking, no pure substances in the material world, neither inside nor outside the laboratory.

In the natural world, a piece of matter is always a complex mixture whose compounds, in terms of pure substances, can be listed only with limited precision. For instance, one can identify a few thousand substances in a simple piece of soil, knowing that this is only the tip of the iceberg. Moreover, while our theoretical understanding might grasp chemical reactions within mixtures of ten or twenty substances under certain conditions, it usually fails to provide comprehensive explanations and predictions beyond that limit. The drawback of adjusting matter in the laboratory to chemical concepts is that both our empirical and theoretical concepts are very limited to understanding the natural world. Even inside the laboratory, material samples never fully meet the conceptual ideal of purity, because of practical limitations of purification procedures and for thermodynamic reasons. Instead, any presumably pure substance can contain impurities at concentrations below the analytical limit. Matter, so to speak, resists purification at a certain degree and thereby chemical conceptualization. Because even the smallest impurity can have, through catalytic effects, a strong impact on chemical properties, there will always be uncertainty in any specific chemical statement.

Such uncertainties, both about natural and laboratory systems, can only be reduced by considerations of relevance, that under this specific condition and for that particular question this or that impurity in a given system is irrelevant. For instance, for many research purposes the gases of the air dissolved in pure liquids do not matter, for others they crucially impact the experiments. That most elements come as a mixtures of isotopes is negligible in many field of 
chemistry, in others it is essential. There are issues for which we may assume pure water to be simply $\mathrm{H}_{2} \mathrm{O}$, many others need to take into account its dissociation, and some even its complex dynamic structure that makes it look like a mixture of hundreds of species.

The complexity of matter forces us to take different perspectives depending on what we want to know. One might object that the limitations are only of practical nature and that future chemistry will push the limits towards the "ideal science", in which every piece of matter can be analyzed with ultimate precision and described by a "Theory of Everything" that takes any possible fact into account. However, apart from the insurmountable practical issues of generating endless information, that ideal runs into serious conceptual problems. From the point of view of ultimate precision, every piece of matter is unique and no longer a sample of a species. If we thus investigate one, two, or hundreds of samples, we could no longer draw general conclusions from our studies about a certain kind of matter, because the notions of both kinds and samples are no longer available. We would then lose the ability to build general concepts and provide general knowledge, on which science essentially rests. If, on the other hand, we later screen the endless information for what is relevant from a certain point of view and build corresponding equivalence classes in order to form general concepts and statements, we would just end up doing what science actually does: building a variety of different approaches depending on what is taken to be relevant. The "Theory of Everything", and its philosophical counterpart of radical nominalism, is therefore a useless and counterintuitive idea in chemistry.

The two reasons for pluralism, multiple aims and epistemic limits, thus act in concert. Chemistry (and probably any science faced with complexity issues) can partially overcome its epistemic limits by diverging according to its different aims.

The following three sections look closer on what methodological pluralism in chemistry means for some exemplary philosophical issues: laws of nature, reductionism, and realism. As much as mainstream debates, with their focus on mathematical physics, have presupposed methodological monism, so much will their concepts and views be useless, even obstructive, for the philosophical understanding of chemistry. As any approach that seeks understanding, also philosophy of science cannot evade the inevitability of pluralism and must develop distinctive approaches for the understanding of each discipline.

\section{Models versus Laws of Nature}

The notion of laws of nature plays an eminent role both in the philosophy and popular representations of science, suggesting that their discovery is the primary task of scientists (for details on the following, see Schummer 2014b). However, at least for the past hundred years, it is hard to find a single law that has been formulated and called so in chemistry, and similarly in physics. Without strict terminological distinctions, chemists call their theoretical findings theories, equations, or, most frequently, models, for good reasons as will be seen below. Moreover, the many so-called laws from the 19th century do not meet the rigorous philosophical requirements such as universality and validity without exceptions that are usually associated with that notion. Even worse, all the so-called limiting laws of physical chemistry (such as the ideal gas law, Rault's law, Henry's law, and so on) are strictly valid only for the ideal case of zero concentration, i.e. for no single real case, which makes standard procedures impossible to fix the universality by limiting the validity through so-called ceteris paribus conditions. Philosophers of chemistry (Christie 1994, Christie \& Christie 2000), considering all that a deficiency, have suggested a more liberal concept of laws of nature so as to cover chemistry by the conceptual apparatus of philosophy of science. However, the problem is not chemistry, but the philosophical misconception of science, according to which all disciplines would have to meet the standards set by philosophers of mathematical physics.

Historically the core of the experimental tradition of science, chemistry has developed its own pluralist methodology of models that radically differs from the monist mathematical 
tradition, out of which the notion of laws emerged (for the two tradition, see Kuhn 1976). Laws, on the one hand, are formulated with universal claims of truth, which can at best later be reduced by ceteris paribus conditions or extended by the reduction of other laws. Models, on the other, are developed on the approximate description of exemplary cases, which can be carefully extended only by modification and sophistication that include parameters to cover their particularities. While a law is the better the more universal it is, a model is improved by precisely calculating, testing, and limiting its area of intended applications with error estimates. There can be no two laws of nature competing with each other for long, because there is only one nature which any law tries to describe truthfully and completely. Different models for the same field of application can peacefully coexist and usefully complement each other, because they might employ different approximations or put different emphasis on different kinds of questions and aspects. Both laws and models are comparable tools for explanations and predictions, but laws assume exclusive explanatory power while models can explain only those aspects they have been built to do so. Laws, if confronted with serious problems, have to be dropped altogether, which results in discontinuities of science and makes previous research appear useless, whereas models can be flexibly adjusted or supplemented by new models. While laws are inherently reductionist in the sense of methodological monism, models are developed in the vein of methodological pluralism.

The two methodological approaches, of laws and of models, are so diametrically opposed to each other that any attempt to mix them or to extend the concept of laws so as to include models runs into counterintuitive, if not absurd, results. Philosophers would do better if they keep the two opposing methodologies strictly apart, because the epistemological issues and their metaphysical implications of one methodology are largely irrelevant for the other.

\section{The Monist Assumption of Reductionism}

From the pluralist perspective, also the debate on whether chemistry is reducible to physics appears misleading. Terms like "chemistry" and "physics" nowadays refer to megadisciplines, which each comprise not only single theories but a plurality of conceptual and methodological knowledge traditions as well as the societal structures that bear the social identity of disciplines.

If we take, for brevity reasons, only the conceptual and methodological traditions that constitute the cognitive side of a mega-discipline, they are, in the case of chemistry, split into hundreds of different research fields (see above). Since they can today only be socially rather than cognitively united under the umbrella of a mega-discipline, it is more than questionable that an entirely different discipline could do better. On the level of sub-disciplines or research fields, there are differences regarding the conceptual apparatus, research aims, and methodological values. It is usually easier to find corresponding agreements between research fields of the same discipline than of different ones, with the exception of bordering areas such as physical chemistry and chemical physics.

How then about the reduction of a single theory of one discipline or subdiscipline through that of another? Nagel (1961, p. 351ff.) once raised the issue with two theories taken from physics, nonchemical thermodynamics and the kinetic theory of gases. In general, however, theories cannot be analyzed and judged in isolation from their aims, which considerably differ between the disciplines. If both serve different (sets of) aims and thus have different areas of intended applications, one cannot simply compare them or even judge one as superior (reducing) over the other (reduced). The idea of reduction of theories makes sense only if the area of intended applications of one is a subset of that of the other. In that case, however, it is hard to see how philosophers can contribute. In science, unlike in speculative philosophy, claims on the area of intended applications are to be made and judged by scientific arguments alone, which is the job of scientists. In the pluralist world of modern science, there is no privileged model that is granted metaphysical status, i.e. the broad-brush 
entitlement of universality that exempt it from clearly delineating its field of application by scientific arguments.

Finally, if a theory of one (sub-)discipline is able to explain a phenomenon or property to the satisfaction of another (sub-)discipline, that counts as a successful case of interdisciplinarity, which makes all parts happy. A case in point would be the quantum chemical explanation of the specific electric conductivity or chemical bonding energy of a substance. Properties, particularly the operationalized ones in the experimental sciences, are not proprietary of a discipline but common ground. Interdisciplinarity consists in sharing and reconfiguring conceptual resources from different origins for the mutual benefit or the solution of a cross-disciplinary issue. Reframing such practice in terms of reduction of one discipline to another would not only miss the conceptual efforts required on both sides, but also introduce hierarchical thinking that is hostile to interdisciplinary collaboration.

In sum, it is difficult to make philosophical sense of the epistemological reduction of one discipline to another. The only cases that can reasonably be discussed, when the area of intended applications of one theory is a subset of that of another, are typical issues of scientific debate, for which philosophers have no particular competence to contribute. They do have, however, for investigating conceptual and methodological differences between disciplines, which makes interdisciplinarity issues a much more promising and useful field of philosophical studies than reduction.

\section{Realism Revisited}

Since the 1970s, philosophers of science have discussed a view they call "scientific realism". Although there exist now dozens of versions, they all share the opposition to "instrumentalism", the view that scientific concepts and theories are judged according to their usefulness regarding epistemic values such as prediction, explanation, classification, synthesis, and so on. However, "instrumentalism" is a truism in science and elsewhere: the epistemic value of something is always assessed on the basis of whether it helps us pursue certain epistemic aims. Within the pluralist constitution of science, it is even necessary to point out for what particular epistemic aim a scientific concept or model is good for in order to improve the division of scientific labor.

The adherents of "scientific realism" instead seek intrinsic values in theories that are independent of epistemic aims, or any aim whatsoever. They claim that certain theories are in a not further explicable way "true". 1 The search for such theories cannot be conducted for epistemic purposes, which would be "instrumentalism", but must be a purpose-free activity. The debate has, of course, focused on distinguishing the latest theories of mathematical and high energy physics (and strangely begun in the USA during the Cold War, when exactly that kind of research was heavily funded for military reasons). By excluding any purpose, including epistemic aims, they have created a very distorted image of science. In contrast, all scientists pursue aims, epistemic or not, and they use terms like "true" much more flexibly, depending on the discipline and always on how much the corresponding concepts have been successful in pursuing various epistemic aims. Moreover, by distinguishing the theories of physics among the vast plurality of research fields, "scientific realists" have not only repeated the received one-sided focus on theoretical science, but also tried to reformulate a version of physicalism. "Scientific realism" is thus only the latest desperate movement to uphold the flag of physicalist monism in the pluralist world of science.

It is therefore overdue to drop "scientific realism" and look for a concept of realism that is meaningful for the pluralist constitution of science in general and chemistry in

\footnotetext{
1 If the truth conditions of a theory consist in all sentences that can possibly be deduced from the theory plus specific assumptions, as a standard view maintains, that would amount to all its possible explanations (postdictions) and predictions. Yet, "scientific realism" wants a theory to be more, making truth an obscure notion.
} 
particular. Hasok Chang $(2012$, ch. 4.2) has already argued in a similar vein that realism is not a matter of belief in the truth of a theory, but an active commitment to the pluralist pursuit of knowledge of the external reality. I will take a slightly different approach in the following sketch (for more details, see Schummer 1996) by returning to the original meanings of realism. In philosophy, realism has been a position opposed to either idealism, nominalism, or skepticism, depending on whether the reality of the outer world or the correspondence of our concepts and knowledge to the world is denied. If we find in the practice of chemistry institutionalized traits that conflict with those views, we have some clues of what realism means here.

Idealists believe in the reality of ideas or, more radically, that only ideas form reality. The view has thrived particularly within rationalism, which rejects sense perceptions and experience as reliable sources of knowledge, and instead seeks contact to its reality through intuition and logical constraints of reasoning. While that undoubtedly plays a role for chemists, most of them seek contact to reality first of all through experimentation in the double meaning of the word. One the one hand, they probe the behavior of material samples under the sophisticated control of the context in order to test or modify a conjecture. On the other, they playfully or systematically explore the behavior of material samples in search for unexpected, surprising results. In both cases, the behavior of the probed material world is considered independent from human will and planning, a material response rather than the intuition of an idea. That is a clear indication that experimental chemists reject idealism and instead favor the corresponding realism as their institutionalized metaphysical view. This kind of realism is fully compatible with methodologically pluralism, because it does not matter what particular aim is pursued or what kind of conceptual framework is presupposed, as long as the rules of experimentation are observed. In theoretical and computational chemistry, where results depend solely on the theoretical input or mathematical algorithms and some given data, that differs however. Thus, within the overall pluralism of chemistry, metaphysical realism has been institutionalized in the methodology of experimental research, while theoretical branches follow a style that is more akin to idealism. The issue is no longer a matter of philosophical interpretation or taste, as it might have been still in the 18th century, but depends on what specific research field we look upon.

The second traditional opposition to realism, nominalism, claims that our classificatory concepts, while being useful ideas for certain human purposes, have no correspondence in the world. We might want to divide up the world into kinds and sub-kinds, but such divisions are only mental constructs rather than kinds whose differences are founded in nature. All that really exists are individual pieces of matter that can at best be related to each other by similarity relations. Originating in medieval metaphysics, it became a powerful modern position from the mechanical philosophy to Logical Positivism, which is difficult to refute in natural history. However, chemistry has long solved the issue for its own purposes by experimentally adjusting the material world in the laboratory to its concepts (Section 4). We divide up mixtures not by mental but by experimental analysis into compounds, and correspondingly compounds into its constitutional elements. And conversely, we make compounds not by mental compositions of properties, but by chemical synthesis. Although the results are not ultimately perfect for practical reasons, as mentioned before, the species thus created are reproducible in any laboratory at any time. No chemist denies that chemical elements and substances are real kinds rather than mental constructs. Even further, if chemists conceive of theoretical entities, i.e. chemical substances that do not exist yet, they reasonably believe in their potential reality, which is the most convincing case of "entity realism" (Schummer 1996, chap. 6), because they know how to realize them in the laboratory by theoretically guided synthesis, as has been done millions of times before. In sum, conceptual realism, as opposed to nominalism, is an unquestioned position in chemistry because it is deeply rooted in its experimental practice. As long as the rules of experimentation are 
observed, species can be developed for different purposes and by different methods, such that conceptual realism is also compatible with pluralism.

The third view opposed to realism, skepticism, denies that we can achieve reliable knowledge about the world. From the aforementioned it immediately follows that this is an untenable position in chemistry. Because chemists, unlike mathematicians or philosophers, seek contact to the outer world through experimentation and because their concepts to describe the world are operationally based in experimental practice, which can be reproduced by anyone at any time, the knowledge thus achieved meets all conditions of objectivity and reliability one can reasonably wish for. Although that, of course, refers only to very basic experimental knowledge, it suffice to refute skepticism in general and to establish a foundation for epistemological realism. We can go further, however, if we drop the idea that theories must be either true or false, which is so vulnerable to skepticism. In the experimental sciences, theories or models, or more generally conceptual frameworks, are not the end but the means of science. Similar to the experimental apparatus, they are tools to probe the world, to pose precise questions for which we expect precise and reliable answers. Like any tools, their quality is a matter of degree, depending on their inner construction (conceptual clarity, logical consistency, degree of sophistication, easiness of use, etc.), and they can be more useful for certain tasks and less so for others. Equipped with the right conceptual and experimental tools, we can measure, for instance, binding energies, inter-atomic distances, activation enthalpies, and other theoretical values, which might lead to further theoretical explanations, classifications, predictions, synthetic strategies, etc. If the conditions and assumptions, which are part of any conceptual approach, are carefully listed, and premature generalization avoided, the skeptic has little to object to other than repeating the assumptions. But why should one expect unconditional knowledge from science? As a rule, scientific knowledge about the external world comes in the form: If we pose a certain question and take this method which includes these restrictions and those assumptions, we get that answer with that degree of certainty. Epistemological realism is thus not only compatible with, but even requires pluralism, because conceptual approaches need to be tailored to specific questions to provide precise and reliable answers. Philosophically speaking, the epistemology that is anchored in the research practice of chemistry is perspectivism.

Once we drop the obscure idea of "scientific realism" and look instead at what chemists do, philosophical realism turns out to be institutionalized in all its three traditional forms: metaphysical, conceptual, and epistemological.

\section{Conclusion: The Advantages of Pluralism}

In Sections 2-4, I have argued that pluralism is, as a matter of fact, the methodological constitution of science in general and chemistry in particular and that it is inevitable for both practical and epistemological reasons. Against that background, pointing out its advantages over monism appears to be obsolete. However, the philosophy of science that has dominated for decades the debate has focused so much on a single, mono-purpose, and exceptionally uniform subdiscipline, mathematical physics, that it has created a strong taste for monism which is difficult to convince of what is obvious. The unspoken implication of monism is that the actual science, with its ever growing divergence into methodologically different disciplines, subdisciplines, and research fields, is a deeply irrational enterprise. In contrast, I suggests that science is a very rational endeavor. That is not an opportunistic statement seeking agreement from scientists. For, if pluralism is both inevitable and serves various epistemological needs that scientists actual have, only a fool would do without it.

There are many other benefits of pluralism, some of which have already been discussed in detail by Hasok Chank (2012, chap. 5.2) or mentioned before. First of all, if we acknowledge that biology, physics, chemistry, geology and so on (as well as correspondingly their various research fields) have different subject matter and different research aims that 
require different methods, it is obvious that monism can pick only a single aspect and disregard the rest. Pluralism instead allows a non-hierarchical division of labor, which in most fields of society is the most effective and successful approach. Moreover, as new kinds of issues arise, either out of the research process or by societal demand, science can flexibly adjust by extending old or developing entirely new approaches. The monist philosopher must ignore all that or reject it as "applied" research not worth studying. Sticking to the glorious past of less than a handful of physical theories, monist philosophy has developed an extreme conservatism without contact with contemporary science and its enormous creativity. In contrast, pluralist philosophy can not only appreciate this aspect but also study its manifold dynamics.

When the division of labor is not so clear-cut, such that different approaches are required to collaborate in a multi-aim project, they can share and combine their resources. Pluralism provides the analytical resources to understand possible barriers of interdisciplinarity, in terms of their different conceptual and methodological views, and mediate between them, whereas the only monist answer to such problems is the hierarchical order by way of impossible discipline reduction. Moreover, combining resources and perspectives has the further advantage that it can create new conceptual and methodological approaches. Because scientific research is all about creating novel understanding, pluralism thus provides the best framework for the methodology of discovery and innovation. In contrast, monist methodologies have largely focused on the futile search for a universal logical method for the retrospective justification of what is already known, e.g., the support of a theory. That, however, considerably differs among disciplines as diverse as, say, geology and mathematics, and among specific research fields, depending on their respective research aims and methods as well as the intended usage of their theories.

Surely competition plays an important role in pluralist science too. Two approaches or models may compete with each other on which is the best one to achieve a certain aim. Such debates help sharpen and elaborate the approaches, or inspire entirely new ones. It may turn out that their aims and areas of intended applications differ more than was expected at first, such that they can supplement each other. If the difference is more fundamental, competition continues, which might result in different research schools and traditions that each develop valuable conceptual and methodological resources further. Because the future of science is for reasons of principle not predictable, including future aims and research questions, final decisions on such competitions would be an unreasonable strategy in science. However, monist philosophy requires such a decision, because there is supposed to be only one "truth". It imposes the inappropriate winner/loser metaphor on science to purge it from the valuable conceptual and methodological resources of the alleged losers. In contrast, pluralist philosophy cannot only study the various ways of solving competitions, but also appreciate continuing competition for epistemological reasons. The more approaches we have, the richer is our perspectival understanding of the world; and the more precisely the approaches are limited, the more reliable is our knowledge. Thus, pluralism allows for two-dimensional progress in science, whereas monism makes the unreasonable demand that scientists produce both methodological and content-based knowledge that would most likely have to be dropped in the future.

Finally, pluralism provides valuable lessons for philosophy of science drawn from the pluralist constitution of science in general and of chemistry in particular. If a philosopher makes general statements about science, the pluralist asks: for which discipline or research field is your statement valid? That prevents reckless generalizations, broadens one-sided views, and allows one to estimate the relevance of philosophical topics among the diversity of science. Three cases in point have been discussed in this paper: the unreasonable extension of the notion of laws of nature from mathematical physics to science in total; the monist assumption in the debate about reductionism; and the misleading conception of "scientific 
realism". Focusing on the actual scientific practice, which is inextricably linked with human aims and purposes, philosophical pluralism is rather in the tradition of pragmatism and strictly opposed to logicism and idealism in the Kantian and Hegelian style. It brings topics to the fore that both matter in science and to which philosophy can make useful contributions, such as the methodology of models, the issues of interdisciplinarity, and the institutionalized forms of realism in scientific practice. Without repeating the mistake of blind generalizations, the philosophical perspective on chemistry can thus help enrich philosophy and explore its resources for the benefit of science.

\section{References}

Bachelard, Gaston (1932): Le pluralisme cohérent de la chimie moderne, Paris: Vrin.

Chang, Hasok (2012): Is Water $\mathrm{H}_{2} \mathrm{O}$ ? Evidence, Realism and Pluralism, Dordrecht: Springer.

Christie, Maureen (1994): "Philosophers versus Chemists Concerning 'Laws of Nature", Studies in History and Philosophy of Science, 25, 613-629.

Christie, Maureen \& Christie, John R. (2000): “'Laws' and 'Theories' in Chemistry Do Not Obey the Rules", in: N. Bhushan \& S. M. Rosenfeld (eds.): Of Minds and Molecules: New Philosophical Perspectives on Chemistry, Oxford: Oxford UP, pp. 34-50.

Fox Keller, Evelyn (2000): The Century of the Gene, Cambridge MA: Harvard UP.

Hoffmann, Roald \& Laszlo, Pierre (1991): "Representation in Chemistry", Angewandte Chemie Int. Ed. Eng., 30, 1-16.

Kellert, Stephen H.; Longino, Helen E. \& Waters, C. Kenneth (eds.) (2006): Scientific Pluralism, Minneapolis: University of Minnesota Press.

Kuhn, Thomas S. (1976): "Mathematical vs. Experimental Traditions in the Development of Physical Science", Journal of Interdisciplinary History, 7, 1-31.

Nagel, Ernest (1961): The Structure of Science: Problems in the logic of scientific explanation London: Routledge \& Kegan Paul.

Price, Derek J. de Solla (1961): Science Since Babylon, New Haven, Yale UP.

Schummer Joachim (1996): Realismus und Chemie, Würzburg: Königshausen \& Neumann.

Schummer, Joachim (1997): "Scientometric Studies on Chemistry II: Aims and Methods of Producing New Chemical Substances", Scientometrics, 39, 125-140.

Schummer, Joachim (1998a): "Physical Chemistry: Neither Fish nor Fowl?”, in: P. Janich, N. Psarros (eds.): The Autonomy of Chemistry, Würzburg: Königshausen \& Neumann, pp. 135-148.

Schummer, Joachim (1998b): "The Chemical Core of Chemistry I: A Conceptual Approach", Hyle-International Journal for Philosophy of Chemistry, 4, 129-162.

Schummer, Joachim (2002): "The Impact of Instrumentation on Chemical Species Identity: From Chemical Substances to Molecular Species", in: P. Morris (ed.), From Classical to Modern Chemistry: The Instrumental Revolution, Cambridge: Royal Society of Chemistry, pp. 188-211.

Schummer, Joachim (2004): "Why do Chemists Perform Experiments?", in: D. Sobczynska, P. Zeidler \& E. Zielonacka-Lis (eds.), Chemistry in the Philosophical Melting Pot, Frankfurt: Lang, pp. 395-410.

Schummer, Joachim (2008): "Science communication across disciplines", in: R. Holliman et al. (eds.): Practising Science Communication in the Information Age: Theorising Professional Practices, Oxford: Oxford UP, pp. 53-66.

Schummer, Joachim (2010): “The Philosophy of Chemistry", in: F. Allhoff (ed.), Philosophy of the Sciences, Blackwell-Wiley, pp. 163-183.

Schummer, Joachim (2014a): Wozu Wissenschaft?, Berlin: Kadmos.

Schummer, Joachim (2014b): "The Preference of Models over Laws of Nature in Chemistry", European Review, 22, no. S1, S87-S101. 